\title{
Clinicopathological features and prognosis in elderly gastric cancer patients: a retrospective cohort study
}

\author{
Guanghui $\mathrm{Xu} \mathbf{u}^{1, *}$ \\ Fan Feng ${ }^{1}, *$ \\ Shushang Liu',* \\ Fei Wang ${ }^{1,2}$ \\ Gaozan Zheng' \\ Qiao Wang ${ }^{1,3}$ \\ Lei Cai' \\ Man Guo' \\ Xiao Lian' \\ Hongwei Zhang' \\ 'Division of Digestive Surgery, Xijing \\ Hospital of Digestive Diseases, The \\ Fourth Military Medical University, \\ Xi'an, Shaanxi, ${ }^{2}$ Department of \\ General Surgery, No 534 Hospital \\ of PLA, Luoyang, ${ }^{3}$ Department of \\ Surgery, No 9l Center Hospital of \\ PLA, Jiaozuo, Henan, China \\ *These authors contributed equally \\ to this work
}

This article was published in the following Dove Press journal: OncoTargets and Therapy

Background: Little is known about the clinicopathological features and prognosis in elderly gastric cancer (GC) patients aged 65-79 years. The aim of this study was to evaluate clinicopathological features and prognosis in elderly GC patients.

Patients and methods: From May 2008 to December 2014, a total of 5,282 GC patients were enrolled in our present study. Patients were divided into elderly and middle-aged groups. The clinicopathological features and clinical outcomes were analyzed.

Results: The proportion of dysphagia was significantly higher in elderly patients than that in middle-aged patients $(P=0.002)$, whereas the proportion of abdominal pain and heartburn was significantly lower in elderly patients than that in middle-aged patients $(P<0.001$ vs $P=0.038$, respectively). The proportion of patients with carbohydrate antigen (CA) 19-9 was significantly higher in elderly patients than that in middle-aged patients $(P=0.009)$. There was no significant difference in clinicopathological features between elderly and middle-aged patients with D2 gastrectomy (all $P>0.05$ ). Age, tumor size, histological type, tumor depth, lymph node metastasis, carcinoembryonic antigen, alpha fetoprotein, CA19-9, and CA125 were independent risk factors for the prognosis of GC patients in univariate and multivariate analyses. Overall survival in elderly patients was significantly reduced compared with middle-aged patients $(P=0.001)$, especially in patients with tumor size $>5 \mathrm{~cm}(P=0.002)$, poorly differentiated tumor $(P<0.000)$, stage III tumor $(P=0.002)$, or normal levels of carcinoembryonic antigen $(P=0.009)$, alpha fetoprotein ( $P=0.002)$, CA19-9 $(P=0.002)$, and CA125 ( $P=0.004)$.

Conclusion: The clinicopathological features of elderly patients were different to those of middle-aged patients. The prognosis for elderly GC patients was significantly worse than for middle-aged patients.

Keywords: gastric cancer, elderly, clinicopathological features, prognosis

\section{Background}

As the world's population ages, gastric cancer (GC) has become a very common cancer in elderly patients, ${ }^{1,2}$ especially in patients aged 65 years and older. ${ }^{3,4}$ Data on the clinicopathological features and prognosis of elderly GC patients are limited and controversial. It was indicated that poorly differentiated tumors were more common in elderly patients. ${ }^{5}$ However, some studies indicated that younger patients exhibited a predominance of poorly differentiated tumor. ${ }^{6,7}$ Furthermore, it was reported that the prognosis of GC in the elderly was worse than that in nonelderly patients because of the aggressive biological behavior and poorly differentiated histology of the tumor. ${ }^{8,9}$ However, Zeeneldin et $\mathrm{al}^{10}$ reported that the prognosis in elderly patients is equivalent to or better than that in nonelderly patients. Moreover, few studies have focused
Correspondence: Hongwei Zhang Division of Digestive Surgery, Xijing Hospital of Digestive Diseases, The Fourth Military Medical University, 127 West Changle Road, 710032 Xi'an, Shaanxi, China

Tel/fax +86 298477 I53।

Email zhanghwfmmu@।26.com 
specifically on the clinicopathological features and prognosis of GC in elderly and middle-aged patients.

Against this background, we retrospectively analyzed the clinicopathological features and prognosis of elderly and middle-aged GC patients with curative surgical resection. The aim of this study was to identify the clinicopathological features and prognosis of GC in elderly patients.

\section{Patients and methods}

\section{Patients and data}

This study was performed in the Xijing Hospital of Digestive Diseases, affiliated with the Fourth Military Medical University. From May 2008 to December 2014, a total of 5,285 consecutive GC patients were enrolled in this study. To compare the prognosis of elderly and middle-aged patients, patients were selected using the inclusion criteria as follows: 1) had undergone a D2 gastrectomy; 2) had no neoadjuvant chemotherapy; 3 ) had no other type of tumor; and 4) had no distant metastasis.

In the present study, elderly patients were defined as those at the top quartile in the age histogram of GC, whereas middle-aged patients were defined as those within the 10 years range around the second quartile point. ${ }^{11}$ The histogram for the 5,285 GC patients is shown in Figure 1, and the top quartile for age included patients older than 65 years. Furthermore, in order to exclude the influence of senility on the overall survival, the elderly patients were defined as those aged 65-79 years. Thus, the elderly group included 815 patients with GC. The second quartile point for age was 58 years, and patients aged 55-64 years were the largest part of the histogram in our department. Therefore, the middle-aged cohort was composed of 1,096 patients aged 55-64 years.
The clinicopathological data including age, gender, tumor location, tumor size, histological type, tumor depth, lymph node metastasis, TNM stage, levels of carcinoembryonic antigen (CEA), alpha fetoprotein (AFP), carbohydrate antigen (CA) 19-9, and CA125 were recorded. The pathological staging was assessed according to the American Joint Committee on Cancer TNM classification of GC (7th edition, 2010). The patients received postoperative chemotherapy according to the NCCN guidelines of GC. A CEA level of $\leq 5 \mu \mathrm{g} / \mathrm{L}$, an AFP level of $\leq 8.1 \mu \mathrm{g} / \mathrm{L}$, a CA19-9 level of $\leq 27 \mathrm{U} / \mathrm{mL}$, and a CA125 level of $\leq 35 \mu \mathrm{g} / \mathrm{mL}$ were considered to be normal. This study was approved by the Ethical Committee of Xijing Hospital, and written informed consent was obtained from all patients. All the patients were followed up twice a year until December 2015.

\section{Statistical analysis}

Data were processed using SPSS 22.0 for Windows (IBM Corporation, Armonk, NY, USA). Discrete variables were analyzed using the Chi-square test or Fisher's exact test. Univariate and multivariate analyses were evaluated by Cox's proportional hazard regression. The overall survival was measured from the time of resection until death or last follow-up. Evaluation for overall survival was obtained by Kaplan-Meier method. $P$-values $<0.05$ were considered statistically significant.

\section{Results}

The clinicopathological features of elderly patients are summarized in Table 1. A total of 5,282 patients were retrospectively analyzed in the study. Among them, 1,381 patients between 65 and 79 years were classified as

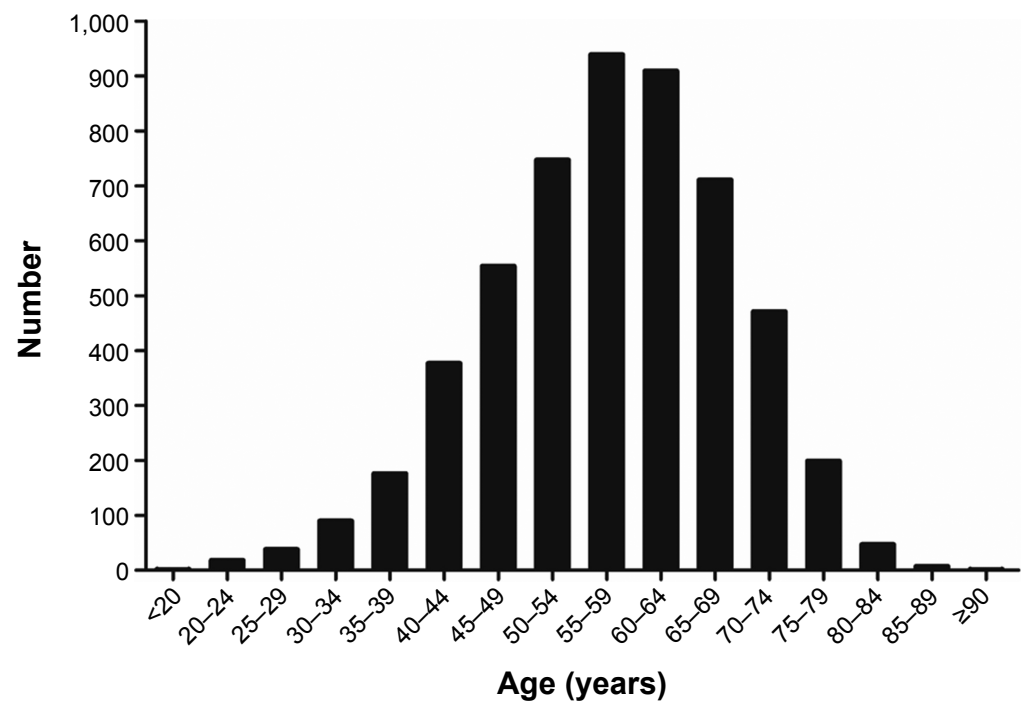

Figure I Distribution of all gastric cancers along with age. 
Table I Clinicopathological characteristics of middle-aged and elderly gastric cancer patients

\begin{tabular}{|c|c|c|c|}
\hline Characteristics & $\begin{array}{l}\text { Elderly } \\
\text { group } \\
(\mathrm{n}=I, 38 I) \\
\end{array}$ & $\begin{array}{l}\text { Middle- } \\
\text { aged group } \\
(n=I, 848)\end{array}$ & $P$-value \\
\hline Age (years), median (range) & $69(65-79)$ & $59(55-64)$ & \\
\hline Gender, n (\%) & & & 0.992 \\
\hline Male & $\mathrm{I}, \mathrm{I} 20(8 \mathrm{I} .10)$ & I,499 (8I.II) & \\
\hline Female & $261(18.90)$ & 349 (18.89) & \\
\hline Abdominal pain, n (\%) & & & $<0.001$ \\
\hline Negative & $631(45.69)$ & $689(37.28)$ & \\
\hline Positive & $750(54.31)$ & I, I59 (62.72) & \\
\hline Abdominal distension, $\mathrm{n}(\%)$ & & & 0.575 \\
\hline Negative & $786(56.92)$ & $\mathrm{I}, 070(57.90)$ & \\
\hline Positive & $595(43.08)$ & $778(42.10)$ & \\
\hline Dysphagia, n (\%) & & & 0.002 \\
\hline Negative & I, I I 7 (80.88) & $\mathrm{I}, 570(84.96)$ & \\
\hline Positive & $264(19.12)$ & $278(15.04)$ & \\
\hline Vomiting, n (\%) & & & 0.050 \\
\hline Negative & I,258 (9I.09) & I,7। 8 (92.97) & \\
\hline Positive & $123(8.91)$ & $130(7.03)$ & \\
\hline Heartburn, n (\%) & & & 0.038 \\
\hline Negative & I, I $80(85.45)$ & I,529 (82.74) & \\
\hline Positive & $201(14.55)$ & $319(17.26)$ & \\
\hline Melena, n (\%) & & & 0.974 \\
\hline Negative & I,249 (90.44) & $\mathrm{I}, 672(90.48)$ & \\
\hline Positive & $132(9.56)$ & $176(9.52)$ & \\
\hline Surgical procedures, n (\%) & & & 0.937 \\
\hline Radical operation & I,223 (88.56) & I,630 (88.20) & \\
\hline Palliative operation & $71(5.14)$ & $100(5.4 I)$ & \\
\hline Exploratory operation & $87(6.30)$ & I I 8 (6.39) & \\
\hline Tumor location, n (\%) & & & $<0.001$ \\
\hline Upper third & $524(37.94)$ & $582(31.49)$ & \\
\hline Middle third & $212(15.35)$ & $371(20.08)$ & \\
\hline Lower third & $520(37.65)$ & $722(39.07)$ & \\
\hline Two-thirds or more & $125(9.05)$ & $173(9.36)$ & \\
\hline Tumor size (cm), n (\%) & & & 0.086 \\
\hline$<5$ & $597(43.23)$ & $855(46.27)$ & \\
\hline$\geq 5$ & $784(56.77)$ & $993(53.73)$ & \\
\hline \multicolumn{2}{|c|}{ Histologic type $\left(\Sigma^{\mathrm{a}}=3,024\right), \mathrm{n}(\%)$} & & 0.472 \\
\hline Well differentiated & $182(14.06)$ & $213(12.31)$ & \\
\hline Moderately differentiated & $396(30.60)$ & $526(30.40)$ & \\
\hline Poorly differentiated & $631(48.76)$ & $865(50.00)$ & \\
\hline Mucinous or signet ring cell & $85(6.57)$ & $126(7.28)$ & \\
\hline Tumor depth $(\Sigma=3,024), \mathrm{n}(\%)$ & & & 0.350 \\
\hline $\mathrm{Tis}+\mathrm{TI}$ & $199(15.38)$ & $300(17.34)$ & \\
\hline $\mathrm{T} 2$ & $207(16.00)$ & 249 (14.39) & \\
\hline T3 & $464(35.86)$ & $631(36.47)$ & \\
\hline $\mathrm{T} 4$ & $424(32.77)$ & $550(31.79)$ & \\
\hline \multicolumn{2}{|c|}{ Lymph node metastasis ${ }^{\mathrm{b}}(\Sigma=3,024), \mathrm{n}(\%)$} & & 0.592 \\
\hline No & $468(36.17)$ & $617(35.66)$ & \\
\hline NI & $231(17.85)$ & $329(19.02)$ & \\
\hline N2 & $223(12.23)$ & $317(18.32)$ & \\
\hline N3 & $372(28.75)$ & $467(26.99)$ & \\
\hline 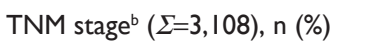 & & & 0.282 \\
\hline I & $273(20.57)$ & $403(22.63)$ & \\
\hline ॥ & $386(29.09)$ & $534(29.98)$ & \\
\hline III & $566(42.65)$ & $701(39.35)$ & \\
\hline IV & $102(7.69)$ & $143(8.04)$ & \\
\hline
\end{tabular}

Table I (Continued)

\begin{tabular}{|c|c|c|c|}
\hline Characteristics & $\begin{array}{l}\text { Elderly } \\
\text { group } \\
(n=I, 38 I)\end{array}$ & $\begin{array}{l}\text { Middle- } \\
\text { aged group } \\
(n=I, 848)\end{array}$ & $P$-value \\
\hline CEA $(\Sigma=2,962), \mathrm{n}(\%)$ & & & 0.270 \\
\hline Negative & 944 (74.92) & I,305 (76.67) & \\
\hline Positive & $316(25.08)$ & $397(23.33)$ & \\
\hline $\operatorname{AFP}(\Sigma=2,854), \mathrm{n}(\%)$ & & & $0.4 I I$ \\
\hline Negative & I, $142(94.54)$ & I,544 (93.80) & \\
\hline Positive & $66(5.46)$ & $102(6.20)$ & \\
\hline CAI 9-9 ( $\Sigma=2,892), \mathrm{n}(\%)$ & & & 0.009 \\
\hline Negative & 927 (75.62) & I,3। 5 (79.26) & \\
\hline Positive & $306(24.82)$ & 344 (20.74) & \\
\hline CAI $25(\Sigma=2,808), \mathrm{n}(\%)$ & & & 0.554 \\
\hline Negative & I,I 07 (92.33) & I,495 (92.9I) & \\
\hline Positive & $92(7.67)$ & I I4 (7.09) & \\
\hline
\end{tabular}

Notes: ${ }^{a}$ Owing to data acquisition, completeness of data is limited. ${ }^{b}$ Seventh UICC/ AJCC TNM classification for gastric cancer.

Abbreviations: AFP, alpha fetoprotein; CA, carbohydrate antigen; CEA, carcinoembryonic antigen; UICC/AJCC, Union for International Cancer Control/American Joint Committee on Cancer.

the elderly group (26.15\%), and 1,848 patients between 55 and 64 years were classified as the middle-aged group $(34.99 \%)$. The most common symptom in elderly patients was abdominal pain $(54.31 \%)$, followed by abdominal distension (43.08\%), dysphagia (19.12\%), heartburn (14.55\%), melena $(9.56 \%)$, and vomiting $(8.91 \%)$. The proportion of dysphagia was significantly higher in elderly patients than that in middle-aged patients ( $19.12 \%$ vs $15.04 \%, P=0.002)$, whereas the proportion of abdominal pain and heartburn were significantly lower in elderly patients than that in middleaged patients $(54.31 \%$ vs $62.72 \%, P<0.001 ; 14.55 \%$ vs $17.26 \%, P=0.038$, respectively). The most common location was upper third (37.94\%), followed by lower third (37.65\%) and middle third $(15.35 \%)$. The proportion of patients with CA19-9 was significantly higher in elderly patients than that in middle-aged patients ( $24.82 \%$ vs $20.74 \%, P=0.009)$.

In order to further analyze the prognosis between middleaged and elderly patients, patients were selected using the inclusion criteria described earlier, which is shown in Figure $2 \mathrm{~A}$ as a flowchart. Overall, 815 elderly patients and 1,096 patients in the middle-aged group were included. The clinicopathological features of the GC in these elderly and middle-aged patients with D2 gastrectomy are summarized in Table 2. There was no significant difference in clinicopathological features between elderly and middle-aged patients (all $P>0.05$ ).

The risk factors for the prognosis of GC in elderly and middle-aged patients with D2 gastrectomy were analyzed using univariate and multivariate analyses. The results indicated that age, tumor location, tumor size, histological type, tumor depth, lymph node metastasis, TNM stage, type of 

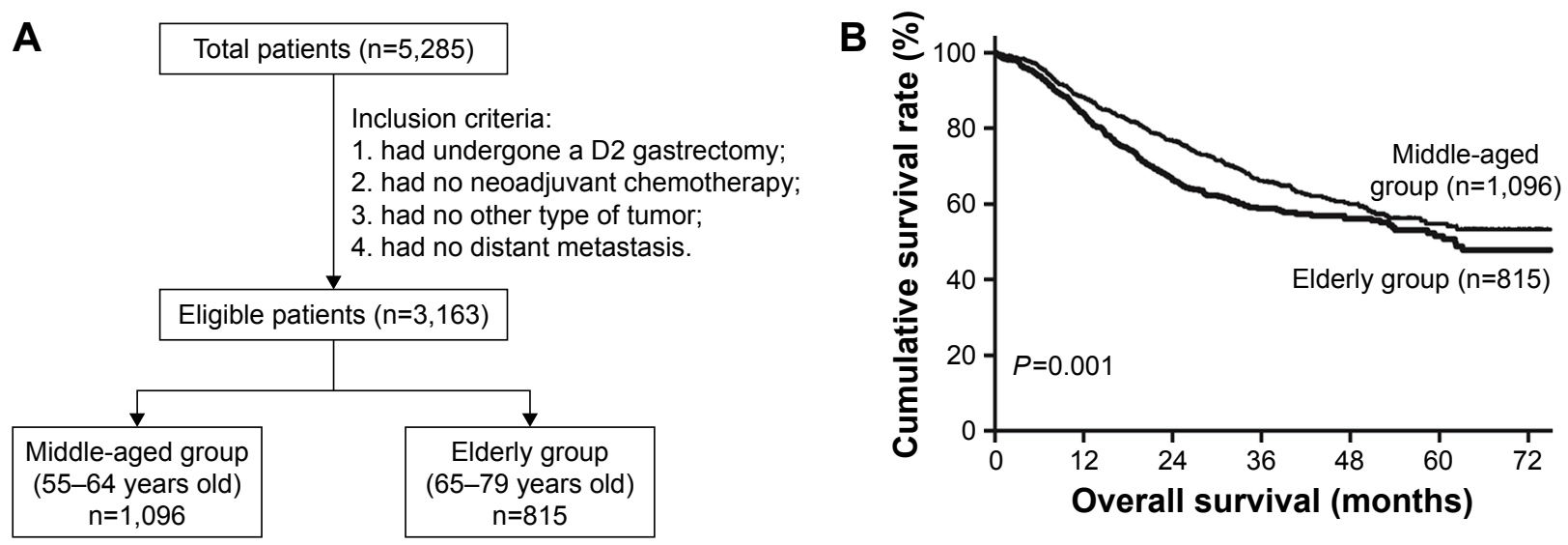

Figure 2 Flowchart of selection process (A) and overall survival between middle-aged and elderly patients with D2 gastrectomy (B)

resection, level of CEA, level of AFP, level of CA19-9, and level of CA125 were predictors for overall survival according to the univariate analysis. In addition, age, tumor size, histological type, tumor depth, lymph node metastasis, level of CEA, level of AFP, level of CA19-9, and level of CA125 were independent risk factors for prognosis by multivariate analysis (Table 3). Overall survival in the elderly group was significantly less than that in the middle-aged group $(P=0.002$, Figure 2B).

As tumor size, histological type, TNM stage, CEA, AFP, CA19-9, and CA125 level were independent risk factors for the prognosis of GC patients, the overall survival between middle-aged and elderly patients was further analyzed within subgroups stratified by the predictors mentioned earlier. The prognosis for elderly patients was significantly worse than that for middle-aged patients with a tumor size $>5 \mathrm{~cm}(P=0.002$, Figure 3B), poorly differentiated status $(P<0.001$, Figure $4 \mathrm{C})$, stage III tumor $(P=0.002$, Figure 5C), normal CEA level ( $P=0.009$, Figure 6A), normal AFP level ( $P=0.002$, Figure 6B), normal CA19-9 level $(P=0.002$, Figure 6C), and normal CA125 level $(P=0.004$, Figure 6D). However, the prognosis of elderly patients was comparable to that of middle-aged patients when the tumor size was $<5 \mathrm{~cm}(P=0.510$, Figure $3 \mathrm{~A})$, with well or moderately differentiated status and mucinous or signet ring cell ( $P=0.974, P=0.566$, and $P=0.051$, respectively, Figure 4A, $\mathrm{B}$, and $\mathrm{D}$ ), stage I or II tumor ( $P=0.407$ or $P=0.338$, respectively, Figure 5A and B), elevated CEA level ( $P=0.093$, Figure 6A), elevated AFP level ( $P=0.459$, Figure 6B), elevated CA19-9 level ( $P=0.494$, Figure 6C), and elevated CA125 level ( $P=0.183$, Figure 6D).

\section{Discussion}

Data on the clinicopathological features and prognosis of elderly GC patients are limited and controversial. In the present study, the clinicopathological features were comparable between elderly and middle-aged GC patients. Age was an independent risk factor for the prognosis of GC, and the prognosis for elderly patients was significantly worse than that for middle-aged patients.

It is widely accepted that the proportion of elderly patients is increasing gradually. Takatsu et $\mathrm{al}^{11}$ reported that GC usually occurred in individuals aged 60-69 years in Japan. However, our results showed that GC was mainly distributed in patients between 55 and 64 years, which were younger than that in Japan. This may be due to more chronic infection, tobacco smoking, or environmental pollution in China. ${ }^{3,12,13}$ The definition of elderly varied among previous reports, which have classified aged as $>70,>75$, and $>80$ years. ${ }^{8,10,14,15}$ In our present study, the top quartile of age was $>65$ years. Moreover, considering the comorbidities associated with very old patients who might influence the prognosis, elderly patients in our present study were defined as those aged 65-79 years. However, the comorbidity in elderly and middle-aged patients and the influence of comorbidity on prognosis were not analyzed in our present study. This requires further investigation.

Previously, the comparison of clinicopathological features has been mainly analyzed between the elderly and young GC patients. ${ }^{11,16}$ However, no study has focused on the clinicopathological features between elderly and middle-aged patients. According to previous reports, ${ }^{17-19}$ the lower third was the most common location for GC in elderly patients. However, tumors located in the upper third were more common in elderly patients in our present study. It is well known that cardiac cancer was associated with gastroesophageal reflux disease (GERD). ${ }^{20,21}$ Moreover, the incidence of GERD increased with age, which was a risk factor for GERD..$^{22,23}$ This may, to some extent, explain the different distribution of tumors in elderly GC patients. 
Table 2 Clinicopathological characteristics of middle-aged and elderly patients with D2 gastrectomy

\begin{tabular}{|c|c|c|c|}
\hline Characteristics & $\begin{array}{l}\text { Elderly } \\
\text { group } \\
(n=8 \mid 5)\end{array}$ & $\begin{array}{l}\text { Middle- } \\
\text { aged group } \\
(n=I, 096)\end{array}$ & $P$-value \\
\hline Age (years), median (range) & 70 (65-79) & $59(55-64)$ & \\
\hline Gender, n (\%) & & & 0.435 \\
\hline Male & $654(80.25)$ & $895(81.66)$ & \\
\hline Female & $161(19.75)$ & $201(18.34)$ & \\
\hline Tumor location, n (\%) & & & 0.304 \\
\hline Upper third & $325(39.88)$ & $396(36.13)$ & \\
\hline Middle third & $181(22.21)$ & $242(22.08)$ & \\
\hline Lower third & $298(36.56)$ & $444(40.5 I)$ & \\
\hline Two-thirds or more & $\mathrm{II}(\mathrm{I} .35)$ & $14(1.28)$ & \\
\hline Tumor size (cm), n (\%) & & & 0.216 \\
\hline$<5$ & $379(46.50)$ & $54 I(49.36)$ & \\
\hline$\geq 5$ & $436(53.50)$ & $555(50.64)$ & \\
\hline Histologic type, n (\%) & & & 0.423 \\
\hline Well differentiated & $107(13.13)$ & $123(11.22)$ & \\
\hline Moderate differentiated & $252(30.92)$ & $323(29.47)$ & \\
\hline Poorly differentiated & $415(50.92)$ & $587(53.56)$ & \\
\hline Mucinous or signet ring cell & $4 \mid(5.03)$ & $63(5.75)$ & \\
\hline Tumor depth, ${ }^{a} \mathrm{n}(\%)$ & & & 0.623 \\
\hline Tis $+\mathrm{TI}$ & $128(|5.7|)$ & $192(17.52)$ & \\
\hline $\mathrm{T} 2$ & $117(14.36)$ & $168(15.33)$ & \\
\hline T3 & $300(36.8 I)$ & $390(35.58)$ & \\
\hline $\mathrm{T} 4$ & $270(33.13)$ & $346(31.57)$ & \\
\hline Lymph node metastasis, ${ }^{\mathrm{a}} \mathrm{n}(\%)$ & & & 0.241 \\
\hline No & $298(36.56)$ & $392(35.77)$ & \\
\hline $\mathrm{NI}$ & $138(16.93)$ & $205(18.70)$ & \\
\hline N2 & $134(16.44)$ & $206(18.80)$ & \\
\hline N3 & $245(30.06)$ & $293(26.73)$ & \\
\hline TNM stage, ${ }^{a} \mathrm{n}(\%)$ & & & $0.67 \mid$ \\
\hline 1 & $185(22.70)$ & $268(24.45)$ & \\
\hline ॥ & $232(28.47)$ & $306(27.92)$ & \\
\hline III & $398(48.83)$ & $522(47.63)$ & \\
\hline Type of resection, n (\%) & & & 0.343 \\
\hline Proximal gastrectomy & $95(11.66)$ & $126(11.50)$ & \\
\hline Distal gastrectomy & $287(35.21)$ & $42 I(38.4 I)$ & \\
\hline Total gastrectomy & $433(53.13)$ & $549(50.09)$ & \\
\hline CEA, n (\%) & & & 0.991 \\
\hline Negative & $633(77.67)$ & 851 (77.65) & \\
\hline Positive & $182(22.33)$ & $245(22.35)$ & \\
\hline AFP, n (\%) & & & 0.240 \\
\hline Negative & 774 (94.97) & $\mathrm{I}, 027(93.70)$ & \\
\hline Positive & $4 \mathrm{I}(5.03)$ & $69(6.30)$ & \\
\hline CAI9-9, n (\%) & & & 0.251 \\
\hline Negative & $633(77.67)$ & $875(79.84)$ & \\
\hline Positive & $182(22.33)$ & $221(20.16)$ & \\
\hline CAI 25, n (\%) & & & 0.703 \\
\hline Negative & $774(94.97)$ & I,045 (95.35) & \\
\hline Positive & $4 \mathrm{I}(5.03)$ & $5 \mathrm{I}(4.65)$ & \\
\hline
\end{tabular}

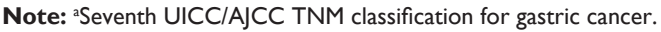

Abbreviations: AFP, alpha fetoprotein; CA, carbohydrate antigen; CEA, carcinoembryonic antigen; UICC/AJCC, Union for International Cancer Control/American Joint Committee on Cancer.

We have confirmed that GC in the elderly is characterized by specific clinicopathological features, including male predominance, poor differentiation, and larger tumor size, which are consistent with previous studies. ${ }^{5,24,25}$ The reason for male predominance remains unclear. It may be related to the greater susceptibility of male patients to Helicobacter pylori infection, alcohol consumption, and smoking. ${ }^{26,27}$ Infection with $H$. pylori and alcohol consumption have been associated with an increased risk for GC. ${ }^{27,28}$ In the present study, the proportion of dysphagia was significantly higher and the proportion of abdominal pain were significantly lower in elderly patients than that in the middle-aged group. Patients with stage III tumors comprised $42.65 \%$ of elderly patients, which was $>13.7 \%-29.3 \%$ reported in previous studies. ${ }^{5,29}$ These may be partially due to hidden clinical manifestations and lack of obvious symptoms in elderly patients with early stage tumors. ${ }^{18}$ Moreover, Liang et $\mathrm{al}^{25}$ reported that the lack of a comprehensive system for tumor screening in China may also result in late diagnosis of GC in elderly patients. It was reported that positive rates of preoperative serum CEA, AFP, CA19-9, and CA125 tended to be higher in elderly patients than that in nonelderly patients. ${ }^{30-32}$ However, the positive rates of these tumor markers except CA19-9 were not comparable between elderly and middle-aged patients in our present study. This may be a result of differences in race, sample size, and population.

It was reported that the overall survival of elderly patients was significantly less than that of nonelderly patients. ${ }^{33,34}$ In our present study, we also found that age was an independent risk factor for the prognosis of GC patients. However, the prognoses were not comparable between the two groups with tumor sizes $<5 \mathrm{~cm}$, well and moderately differentiated status, stage I and II tumors, elevated CEA level, elevated AFP level, elevated CA19-9 level, and elevated CA125 level. These issues require further investigation.

Treatment for elderly GC patients has been criticized. ${ }^{35}$ Factors such as comorbidity and decreased functional status may influence the selection of treatment strategies for elderly patients. One of the main concerns with gastrectomy in the elderly is palliative operation or radical dissection. Elderly patients are considered to be high risk for major surgery because of decreasing functional status. Thus, the Japanese guidelines for GC suggest that $\mathrm{R} 0$ resection with at least limited lymph node dissection should be considered as the first choice treatment for elderly GC patients. ${ }^{36}$ Takeshita et $\mathrm{al}^{17}$ also reported that limited lymph node dissection in elderly patients did not decrease overall survival of GC patients. However, several studies have reported that complications related surgery could be reduced and prognosis could be improved in elderly patients following advances in surgical and anesthesiological techniques. ${ }^{9,29,37}$ Thus, the optimal extent of lymphadenectomy during gastrectomy needs further investigations for elderly GC patients. 
Table 3 Univariate and multivariate analyses of prognostic factors for patients with D2 gastrectomy

\begin{tabular}{|c|c|c|c|c|c|c|}
\hline \multirow[t]{2}{*}{ Parameter } & \multicolumn{3}{|c|}{ Univariate analysis } & \multicolumn{3}{|c|}{ Multivariate analysis } \\
\hline & $\beta$ & HR (95\% Cl) & $P$-value & $\beta$ & HR (95\% Cl) & $P$-value \\
\hline Age & 0.259 & 1.295 (I.102-I.522) & 0.002 & 0.259 & $1.296(1.102-1.524)$ & 0.002 \\
\hline Gender & 0.022 & $1.023(0.834-1.254)$ & 0.830 & -0.088 & $0.916(0.744-1.127)$ & 0.406 \\
\hline Tumor location & -0.093 & $0.911(0.832-0.996)$ & 0.042 & -0.001 & $0.999(0.911-1.096)$ & 0.989 \\
\hline Tumor size & 1.143 & $3.135(2.616-3.757)$ & 0.000 & 0.439 & 1.551 (I.272-1.89I) & 0.000 \\
\hline Histologic type & -0.245 & $0.783(0.708-0.866)$ & 0.000 & -0.106 & $0.899(0.817-0.989)$ & 0.029 \\
\hline Tumor deptha & 0.827 & $2.287(2.060-2.539)$ & 0.000 & 0.469 & $1.599(1.363-1.875)$ & 0.000 \\
\hline Lymph node metastasis $^{a}$ & 0.676 & 1.965 (1.824-2.117) & 0.000 & 0.466 & $1.593(1.40 \mid-1.812)$ & 0.000 \\
\hline TNM stage $\mathrm{e}^{\mathrm{a}}$ & 1.182 & $3.260(2.828-3.760)$ & 0.000 & -0.065 & $0.937(0.692-1.268)$ & 0.672 \\
\hline Type of resection & $-0.44 I$ & $0.643(0.566-0.731)$ & 0.000 & 0.071 & $1.073(0.937-1.228)$ & 0.306 \\
\hline CEA & 0.836 & 2.307 (I.94I-2.742) & 0.000 & 0.353 & $1.424(1.183-1.715)$ & 0.000 \\
\hline AFP & 0.640 & $\mathrm{I} .897(\mathrm{I} .444-2.493)$ & 0.000 & 0.311 & $1.365(1.030-1.809)$ & 0.030 \\
\hline CA199 & 0.692 & $1.998(1.677-2.380)$ & 0.000 & 0.280 & $1.324(1.102-1.59 \mid)$ & 0.003 \\
\hline CAI 25 & 1.244 & $3.469(2.624-4.585)$ & 0.000 & 0.754 & $2.125(I .60 I-2.82 I)$ & 0.000 \\
\hline
\end{tabular}

Note: aSeventh UICC/AJCC TNM classification for gastric cancer.

Abbreviations: AFP, alpha fetoprotein; CA, carbohydrate antigen; CEA, carcinoembryonic antigen; HR, hazard ratio; UICC/AJCC, Union for International Cancer Control/ American Joint Committee on Cancer.

A

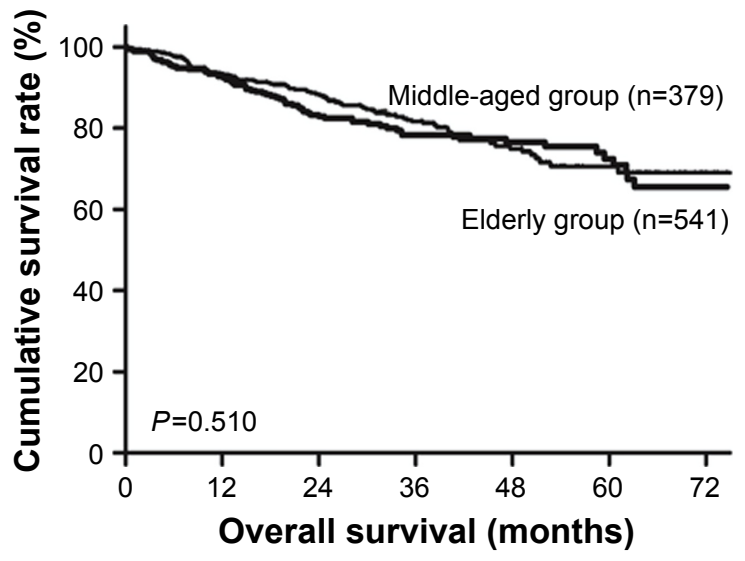

B

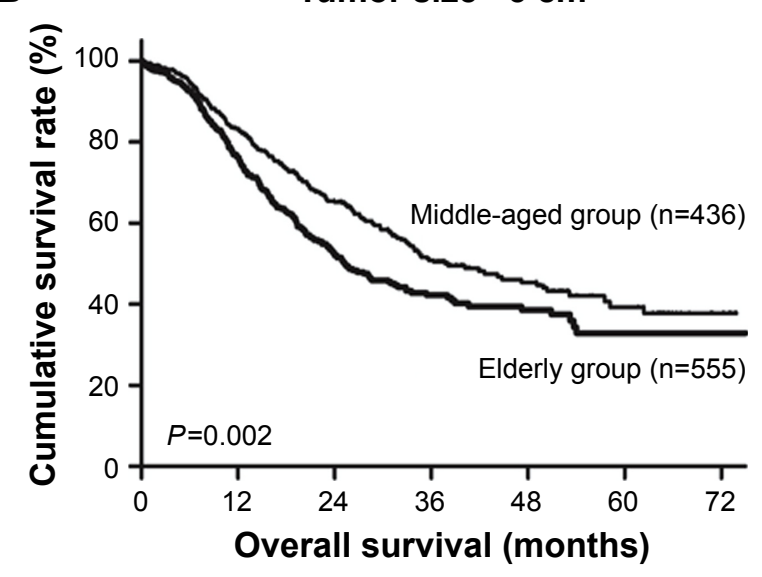

Figure 3 Overall survival of patients based on tumor size.

Note: The overall survival for elderly and middle-aged patients with tumor size $<5 \mathrm{~cm}$ (A) and $>5 \mathrm{~cm}$ (B).

A

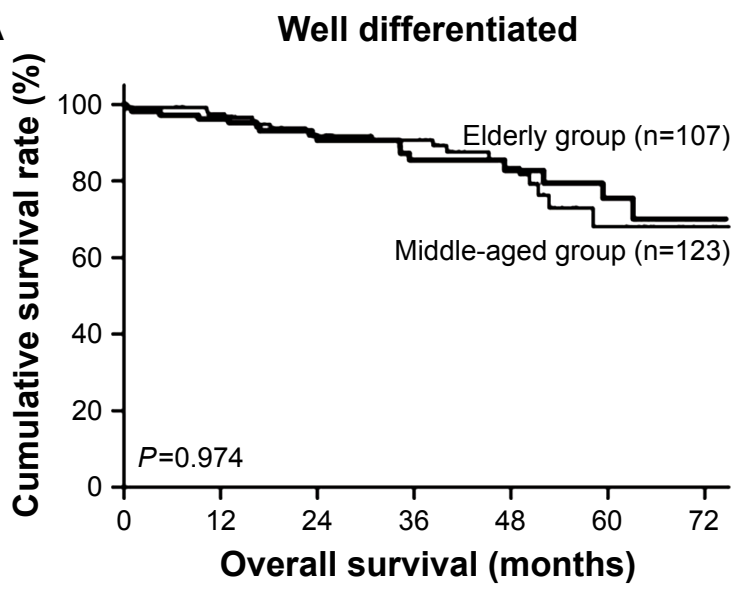

B

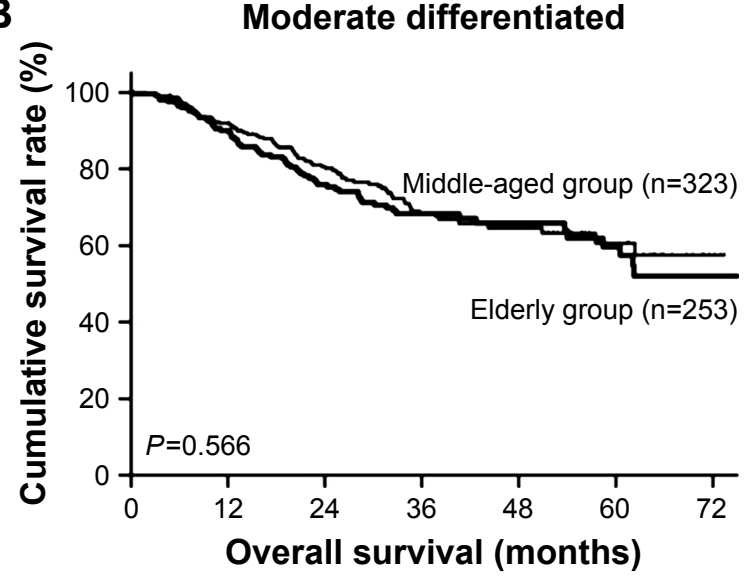

Figure 4 (Continued) 
C

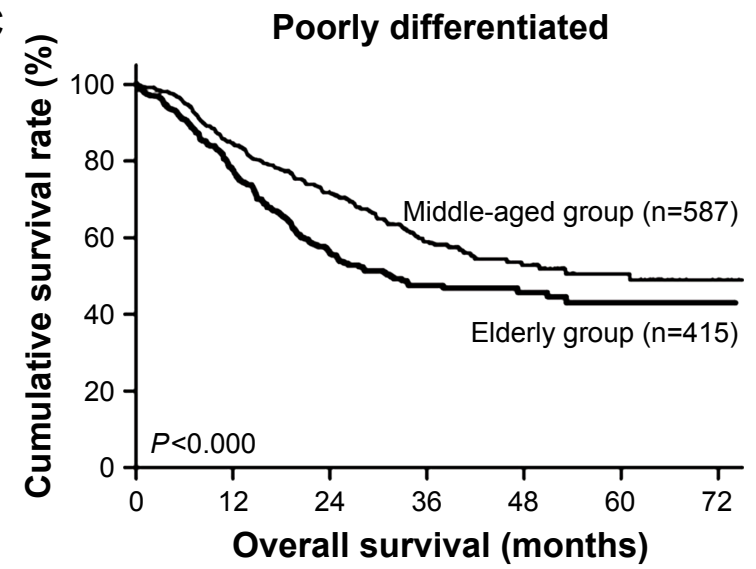

D

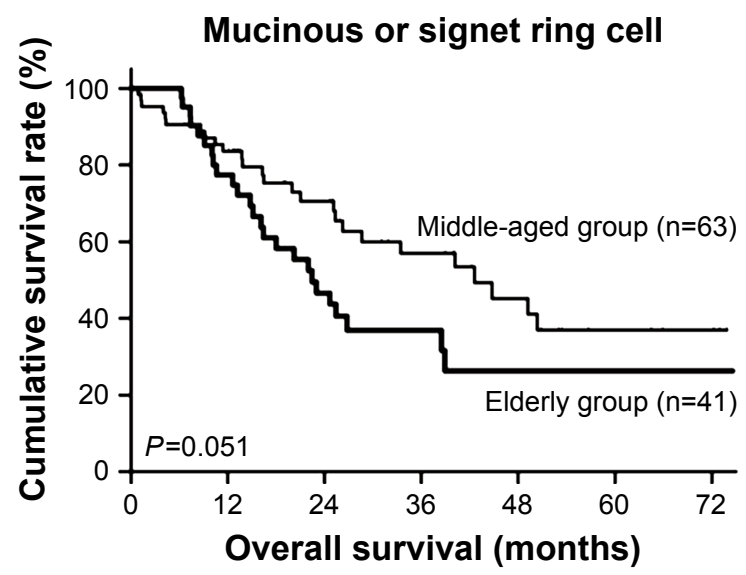

Figure 4 Overall survival of patients based on histological type.

Note: The overall survival for elderly and middle-aged patients with well-differentiated status (A), moderately differentiated status (B), poorly differentiated status (C), and mucinous or signet ring cell status (D).

There are some limitations to the present study. First, the retrospective design in a single center might lead to selection bias. Second, the data for comorbidities in elderly and middle-aged patients and the influence of comorbidities on prognosis were not analyzed. These questions require further investigation.

\section{A}

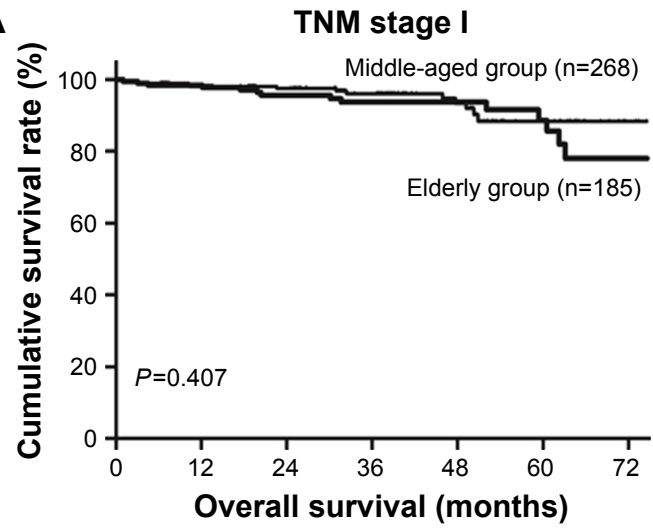

\section{Conclusion}

The clinicopathological features of elderly patients were different to those of middle-aged patients. The prognosis of elderly GC patients with D2 gastrectomy was significantly worse than that of middle-aged patients, especially in patients with a tumor of $>5 \mathrm{~cm}$, a poorly differentiated tumor,

\section{B}

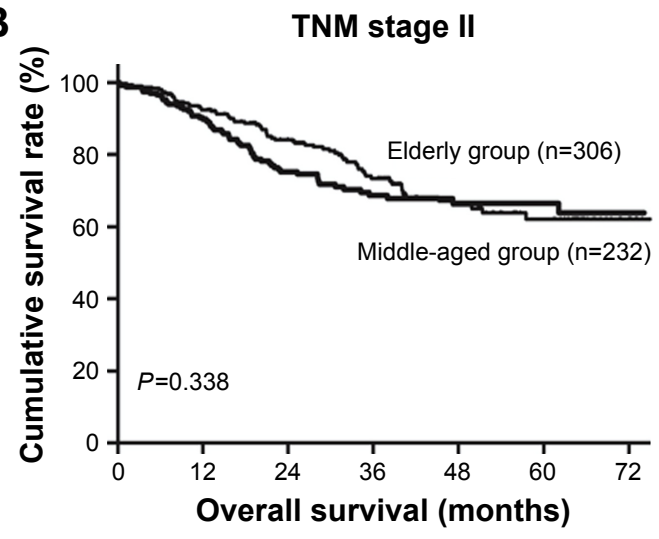

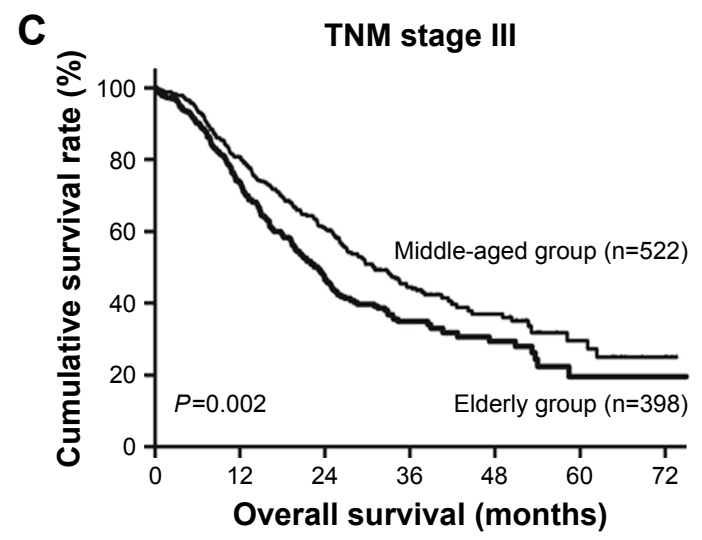

Figure 5 Overall survival of patients based on TNM stage.

Note: The overall survival for elderly and middle-aged patients with stage I tumor (A), stage II tumor (B), and stage III tumor (C). 


\section{A}

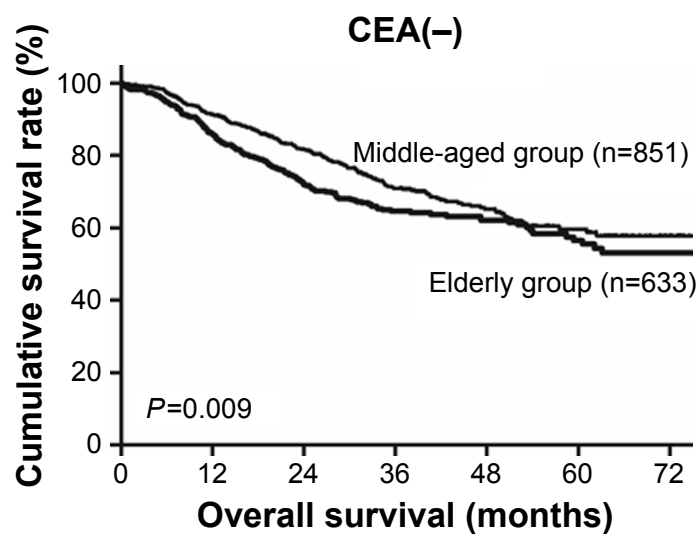

B

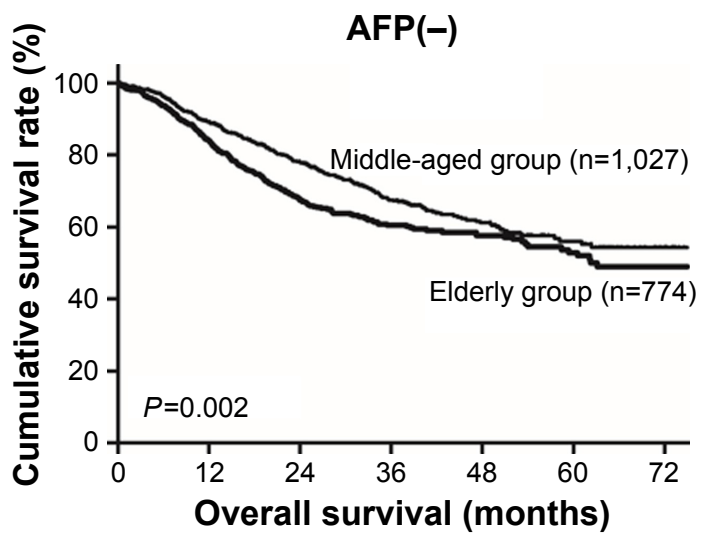

C

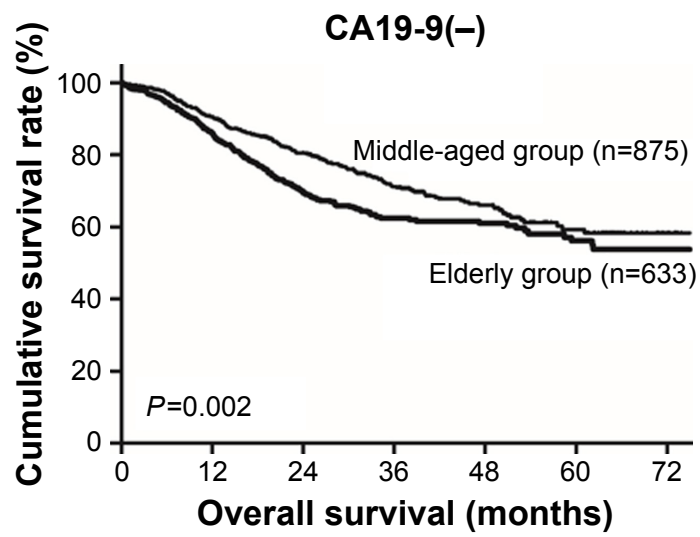

D

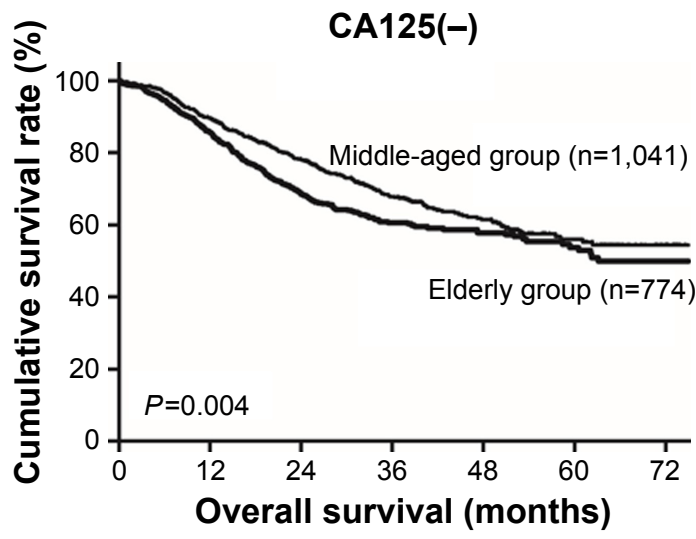

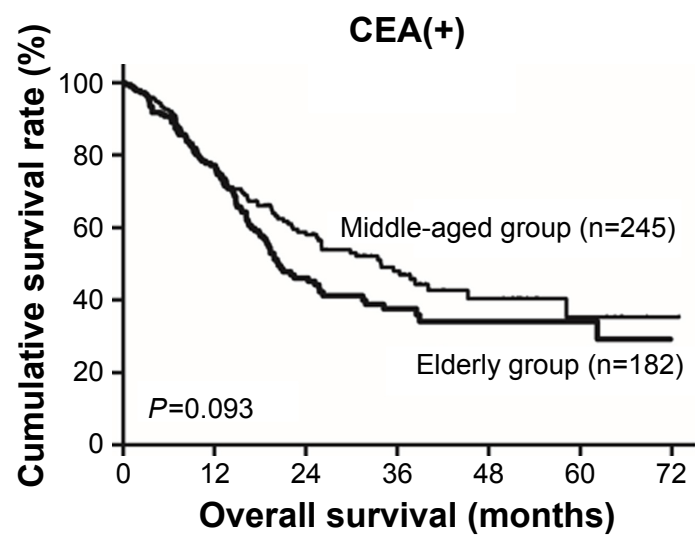
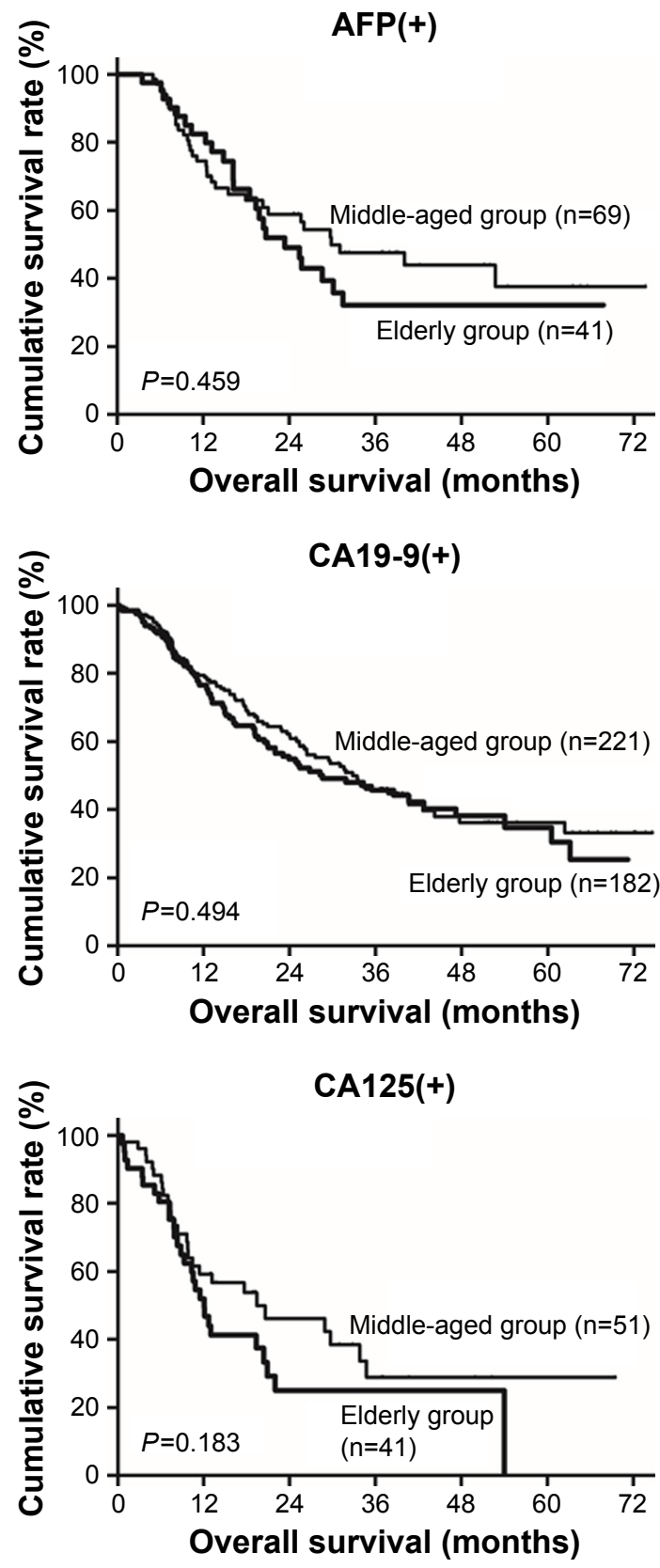

Figure 6 Overall survival of patients based on tumor markers.

Note: The overall survival for elderly and middle-aged patients with normal and elevated CEA level (A), normal and elevated AFP level (B), normal and elevated CA19-9 level (C), and normal and elevated CAI25 level (D).

Abbreviations: AFP, alpha fetoprotein; CA, carbohydrate antigen; CEA, carcinoembryonic antigen. 
a stage III tumor, or normal levels of CEA, AFP, CA19-9, or CA125.

\section{Availability of data and materials}

The data sets supporting the conclusions of this article are included within the article. Data sets cannot be directly shared on public repositories due to the national personal data protection act.

\section{Acknowledgments}

We wish to thank Shuao Xiao and Xuewen Yang for their help with the collection of data. We express our gratitude to Professor Daiming Fan for polishing the article. This study was supported in part by grants from the National Natural Scientific Foundation of China (nos 81502403, 8167242, 31100643, 31570907, 81572306, and XJZT12Z03).

\section{Author contributions}

$\mathrm{HZ}$ and GX designed and supervised the study. GX, FF, and SL drafted the article. FW, GZ, and LC collected the data and generated the clinical database. QW, MG, and XL interpreted the data and performed the statistical analyses. $\mathrm{HZ}$ and FF revised the article. All authors contributed toward data analysis, drafting and critically revising the paper and agree to be accountable for all aspects of the work.

\section{Disclosure}

The authors report no conflicts of interest in this work.

\section{References}

1. Bray F, Jemal A, Grey N, Ferlay J, Forman D. Global cancer transitions according to the Human Development Index (2008-2030): a populationbased study. Lancet Oncol. 2012;13(8):790-801.

2. Marugame T, Dongmei Q. Comparison of time trends in stomach cancer incidence (1973-1997) in East Asia, Europe and USA, from cancer incidence in five continents Vol. IV-VIII. Jpn J Clin Oncol. 2007;37(3):242-243.

3. Chen $\mathrm{W}$, Zheng R, Baade PD, et al. Cancer statistics in China, 2015. CA Cancer J Clin. 2016;66(2):115-132.

4. Ferlay J, Shin HR, Bray F, Forman D, Mathers C, Parkin DM. Estimates of worldwide burden of cancer in 2008: GLOBOCAN 2008. Int J Cancer. 2010;127(12):2893-2917.

5. Lim JH, Lee DH, Shin CM, et al. Clinicopathological features and surgical safety of gastric cancer in elderly patients. J Korean Med Sci. 2014;29(12):1639-1645.

6. Wang Z, Xu J, Shi Z, et al. Clinicopathologic characteristics and prognostic of gastric cancer in young patients. Scand J Gastroenterol. 2016;51(9):1043-1049.

7. Zu H, Wang H, Li C, Kang Y, Xue Y. Clinico-pathological features and prognostic analysis of gastric cancer patients in different age groups. Hepatogastroenterology. 2015;62(137):225-230.

8. Schlesinger-Raab A, Mihaljevic AL, Egert S, et al. Outcome of gastric cancer in the elderly: a population-based evaluation of the Munich Cancer Registry. Gastric Cancer. 2015;19(3):713-722.

9. Fujiwara S, Noguchi T, Harada K, Noguchi T, Wada S, Moriyama H. How should we treat gastric cancer in the very elderly? Hepatogastroenterology. 2012;59(114):620-622.
10. Zeeneldin AA, Ramadan H, El GM, Saber MM, Elgamal D, Sherisher MA. Gastric carcinoma at Tanta Cancer Center: a comparative retrospective clinico-pathological study of the elderly versus the non-elderly. J Egypt Natl Canc Inst. 2014;26(3):127-137.

11. Takatsu Y, Hiki N, Nunobe S, et al. Clinicopathological features of gastric cancer in young patients. Gastric Cancer. 2016;19(2):472-478.

12. Massaquoi LD, Li M, Wang J, Ma J, Yuan M, Liu DW. Mortality analysis on wastewater exposure in Shijiazhuang, Hebei, China, from 2007 to 2011. Int J Environ Health Res. 2015;25(2):214-227.

13. Cao L, Yu J. Effect of Helicobacter pylori infection on the composition of gastric microbiota in the development of gastric cancer. Gastrointest Tumors. 2015;2(1):14-25.

14. Arai T, Takubo K. Clinicopathological and molecular characteristics of gastric and colorectal carcinomas in the elderly. Pathol Int. 2007; 57(6):303-314.

15. Kwon IG, Cho I, Guner A, Kim HI, Noh SH, Hyung WJ. Minimally invasive surgery as a treatment option for gastric cancer in the elderly: comparison with open surgery for patients 80 years and older. Surg Endosc. 2015;29(8):2321-2330.

16. Hsieh FJ, Wang YC, Hsu JT, Liu KH, Yeh CN. Clinicopathological features and prognostic factors of gastric cancer patients aged 40 years or younger. J Surg Oncol. 2012;105(3):304-309.

17. Takeshita H, Ichikawa D, Komatsu S, et al. Surgical outcomes of gastrectomy for elderly patients with gastric cancer. World J Surg. 2013; 37(12):2891-2898.

18. Takeuchi D, Koide N, Suzuki A, et al. Postoperative complications in elderly patients with gastric cancer. J Surg Res. 2015;198(2):317-326.

19. Arai T, Esaki Y, Inoshita N, et al. Pathologic characteristics of gastric cancer in the elderly: a retrospective study of 994 surgical patients. Gastric Cancer. 2004;7(3):154-159.

20. Mukaisho K, Nakayama T, Hagiwara T, Hattori T, Sugihara H. Two distinct etiologies of gastric cardia adenocarcinoma: interactions among pH, Helicobacter pylori, and bile acids. Front Microbiol. 2015;6:412.

21. Patti MG, Waxman I. Gastroesophageal reflux disease: from heartburn to cancer. World J Gastroenterol. 2010;16(30):3743-3744.

22. Imagama S, Hasegawa Y, Wakao N, Hirano K, Hamajima N, Ishiguro N Influence of lumbar kyphosis and back muscle strength on the symptoms of gastroesophageal reflux disease in middle-aged and elderly people. Eur Spine J. 2012;21(11):2149-2157.

23. Sakaguchi M, Oka H, Hashimoto T, et al. Obesity as a risk factor for GERD in Japan. J Gastroenterol. 2008;43(1):57-62.

24. Saif MW, Makrilia N, Zalonis A, Merikas M, Syrigos K. Gastric cancer in the elderly: an overview. Eur J Surg Oncol. 2010;36(8):709-717.

25. Liang YX, Deng JY, Guo HH, et al. Characteristics and prognosis of gastric cancer in patients aged $>/=70$ years. World $J$ Gastroenterol. 2013;19(39):6568-6578.

26. Hwang JJ, Lee DH, Lee AR, et al. Characteristics of gastric cancer in peptic ulcer patients with Helicobacter pylori infection. World $J$ Gastroenterol. 2015;21(16):4954-4960.

27. Tong GX, Liang H, Chai J, et al. Association of risk of gastric cancer and consumption of tobacco, alcohol and tea in the Chinese population. Asian Pac J Cancer Prev. 2014;15(20):8765-8774.

28. Parsonnet J, Friedman GD, Vandersteen DP, et al. Helicobacter pylori infection and the risk of gastric carcinoma. N Engl J Med. 1991;325(16): $1127-1131$.

29. Dittmar Y, Rauchfuss F, Gotz M, Scheuerlein H, Jandt K, Settmacher U. Impact of clinical and pathohistological characteristics on the incidence of recurrence and survival in elderly patients with gastric cancer. World J Surg. 2012;36(2):338-345.

30. Zhou YC, Zhao HJ, Shen LZ. Preoperative serum CEA and CA19-9 in gastric cancer - a single tertiary hospital study of 1,075 cases. Asian Pac J Cancer Prev. 2015;16(7):2685-2691.

31. Sun Z, Zhang N. Clinical evaluation of CEA, CA19-9, CA72-4 and CA125 in gastric cancer patients with neoadjuvant chemotherapy. World J Surg Oncol. 2014;12:397.

32. Chen Y, Qu H, Jian M, Sun G, He Q. High level of serum AFP is an independent negative prognostic factor in gastric cancer. Int $J$ Biol Markers. 2015;30(4):e387-e393. 
33. Lu J, Huang CM, Zheng CH, et al. Short- and long-term outcomes after laparoscopic versus open total gastrectomy for elderly gastric cancer patients: a propensity score-matched analysis. J Gastrointest Surg. 2015; 19(11):1949-1957.

34. Gretschel S, Estevez-Schwarz L, Hunerbein M, Schneider U, Schlag PM. Gastric cancer surgery in elderly patients. World J Surg. 2006;30(8): $1468-1474$.

35. Thompson A, Cone R, Gao H, Hammond E, Fraser D, Back MF. Is advanced age a barrier to effective cancer treatment? The experience of nonagenarians receiving radiation therapy. Asia Pac J Clin Oncol. 2012; $8(3): 255-259$
36. Japanese Gastric Cancer Association. Japanese gastric cancer treatment guidelines 2010 (ver. 3). Gastric Cancer. 2011;14(2):113-123.

37. Shin HS, Oh SJ, Suh BJ. Factors related to morbidity in elderly gastric cancer patients undergoing gastrectomies. J Gastric Cancer. 2014; 14(3):173-179.

\section{Publish your work in this journal}

OncoTargets and Therapy is an international, peer-reviewed, open access journal focusing on the pathological basis of all cancers, potential targets for therapy and treatment protocols employed to improve the management of cancer patients. The journal also focuses on the impact of management programs and new therapeutic agents and protocols on

\section{Dovepress}

patient perspectives such as quality of life, adherence and satisfaction. The manuscript management system is completely online and includes a very quick and fair peer-review system, which is all easy to use. Visit http://www.dovepress.com/testimonials.php to read real quotes from published authors. 